\title{
Antiphospholipid Syndrome and Multiple Ischemic Strokes in a Patient with Myasthenia Gravis
}

\author{
MASAHIDE KAJI, YOSHIHIRO SATO, HARUKO KUNOH, AYA WATANABE, \\ HISAMICHI AIZAWA*, KOTARO OIZUMI* AND TOSHI ABE** \\ Department of Neurology, Kurume University Medical Center, Kurume 839-0863 and \\ Departments of Medicine* and Radiology**, Kurume University School of Medicine, \\ Kurume 830-0011, Japan
}

\begin{abstract}
Summary: Little is known about ischemic stroke occurrence in patients with myasthenia gravis (MG), although antiphospholipid antibodies are detectable in many MG patients. A 47-year-old woman with a 20-year history of generalized MG had an acute onset of right hemiparesis. She had undergone thymectomy 10 years previously and was treated for phlebothrombosis of the lower extremity 3 years previously. Computed tomography (CT) demonstrated an old infarct in the left frontal lobe and a new lesion in the right parietal lobe. Multiple small cortical and subcortical infarcts were demonstrated on fluid attenuated inversion recovery (FLAIR) images. Thrombocytopenia (5.9 $\times 10^{4} / \mu \mathrm{L}$ ), a prolonged activated partial thromboplastin time (aPTT; $50.2 \mathrm{sec}$ ), and an elevation of $\beta_{2}$-lgG-glycoprotein I anticardiolipin antibodies ( $\beta_{2}$-GPlaCL; $55.7 \mathrm{U} / \mathrm{mL}$ ) were observed. Neurological defects improved significantly over 2 weeks. She then was treated with oral prednisolone (30 $\mathrm{mg} /$ day) for 18 months, with resolution of laboratory abnormalities and no new cerebrovascular events or findings on imaging. We believe that our patient's multiple infarcts are caused by antiphospholipid antibodies and recommend glucocorticoid therapy to prevent recurrent of ischemic stroke in similar case.
\end{abstract}

Key words antiphospholipid antibodies, ischemic stroke, myasthenia gravis, steroid therapy, stroke

\section{INTRODUCTION}

Although antiphospholipid antibodies are not uncommon in patients with myasthenia gravis (MG) [1-4] and cerebral infarction frequently complicates anti-phospholipid syndrome (APS) [5,6], little is known about the occurrence of ischemic stroke in MG patients. We report an MG patient with an elevated serum antiphospholipid antibody titer who developed multiple ischemic strokes. Recurrence was prevented by glucocorticoid administration.

\section{CASE REPORT}

A 47-year-old woman with a 20-year history of generalized MG suddenly developed weakness of the right upper limb. She had been treated with warfarin for experienced phlebothrombosis of the left lower extremity 3 years previously, and had undergone thymectomy 10 years after initial diagnosis of MG. Other prior treatment included prednisolone until 3 years before the stroke and ongoing treatment with pyridostigmine bromide which was fairly effective in controlling myasthenia even after prednisolone was discontinued. She was able to live independently, although some diplopia occurred and moderate weakness of arms and legs occurred with prolonged exertion. No history of spontaneous abortion, skin lesions, uveitis, arthritis, cardiac disease, or previous cerebrovascular events was present.

On examination, blood pressure was 120/80 mmHg; no carotid bruits or cardiac murmurs were audible. She was alert with normal memory; aphasia, apraxia and agnosia were not observed. No diplopia 

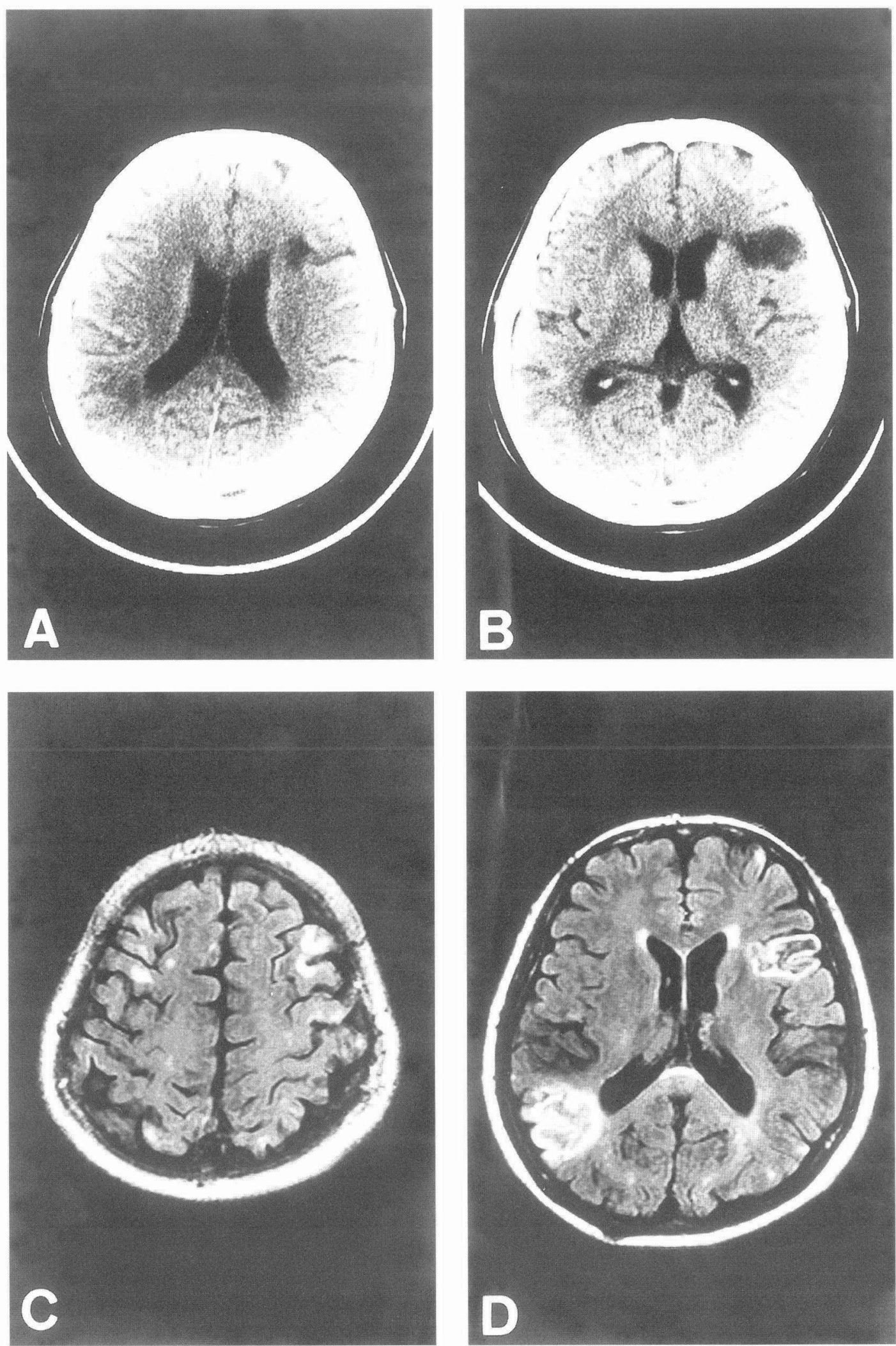

Fig. 1. Initial imaging studies. A, B. Computed tomography scan 2 days after onset of right hemiparesis showed areas of decreased attenuation consistent with infarction in the left frontal and right parietal lobes. The attenuation decrease in was marked in the left frontal lobe and only slight in the right parietal lobe. C, D. Fluid attenuated inversion recovery (FLAIR) images 4 days after stroke onset disclosed multiple small cortical and subcortical infarcts in addition to the two larger lesions. 

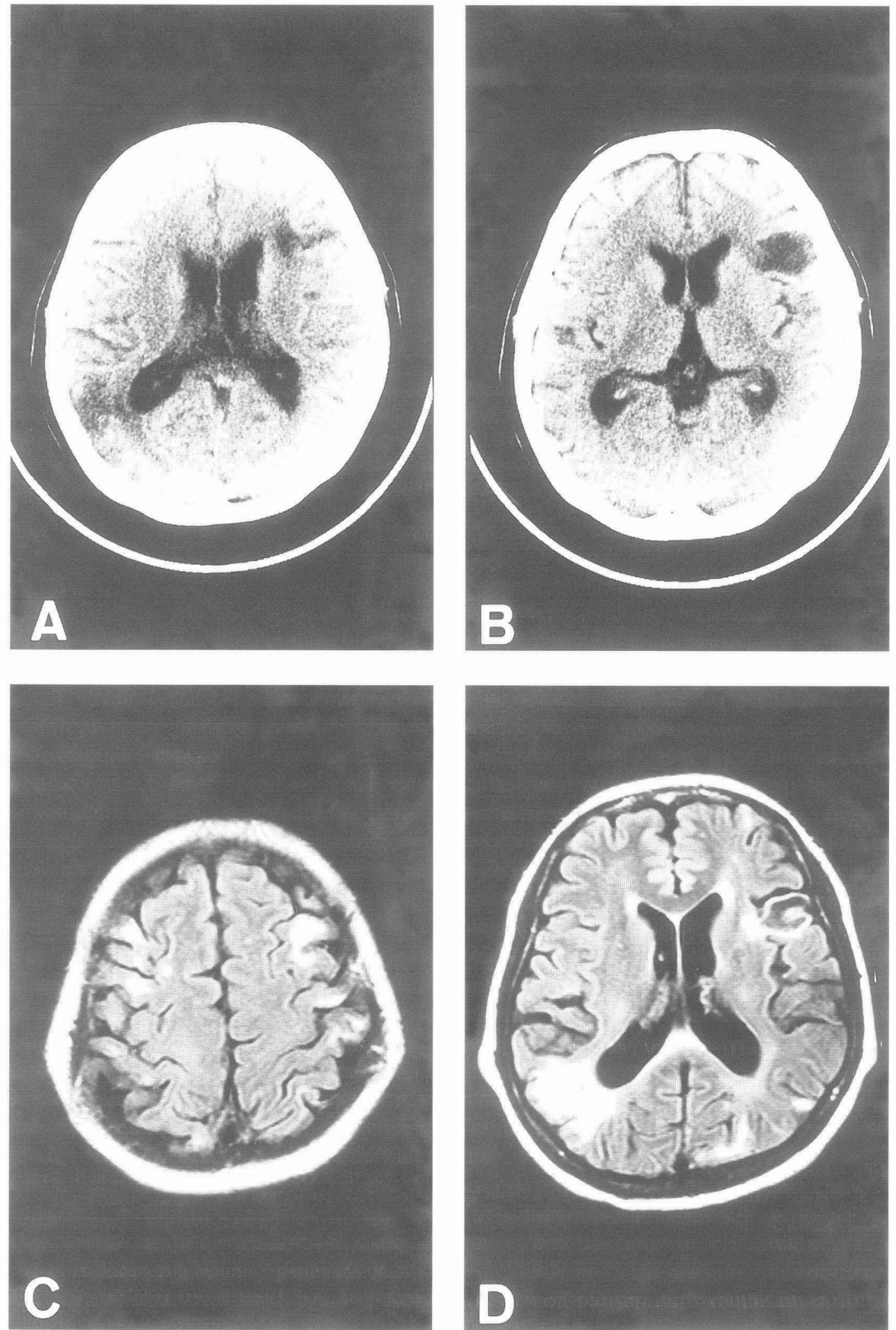

Fig. 2. Follow-up imaging. A, B. Computed tomography 18 months after clinical stroke onset showed further decrease in attenuation in the right parietal lobe, and no new lesions. C, D. Fluid attenuated inversion recovery (FLAIR) images 18 months after stroke onset revealed no new lesions. 
or ptosis was evident. In addition to a nasal voice and mild generalized limbs weakness, moderate right hemiparesis without sensory impairment was present, mainly in the upper limb. A Chaddock sign was present on the right. Noncontrast computed tomography (CT) disclosed two areas (left frontal and right parietal) with decreased attenuation suggesting infarction. Decrease the attenuation was marked in the left frontal lobe but very slight in the right parietal lobe (Figs 1A and B). Four days after onset, only the lesion in the right parietal lobe was enhanced on CT with contrast. Magnetic resonance imaging (MRI) revealed left frontal and right parietal lesions, as seen on CT. Fluid attenuated inversion recovery (FLAIR) images disclosed multiple small cortical and subcortical infarcts in addition to the other two lesions (Figs $1 C$ and D). Small lesions in the left frontal cortex were felt to be responsible for her right pure motor hemiparesis. MR angiography (MRA) showed no narrowing or occlusion.

Negative laboratory studies included a normal white blood cell count, C-reactive protein, hemoglobin $\mathrm{A}_{1 \mathrm{C}}$, total cholesterol, prothrombin time, antithrombin III, rheumatoid factor, LE preparation, anti-double-stranded DNA IgG antibody, antineutrophil cytoplasmic antibody, serologic tests for syphilis, and a test for immune complexes. An international normalized ratio (INR) was 1.11. Abnormal laboratory results included thrombocytopenia $(5.9 \times$ $10^{4} / \mu \mathrm{L}$ ), prolonged activated partial thromboplastin time (aPTT; $50.2 \mathrm{sec}$; normal, 24 to 43) and an elevated $\beta_{2}$-IgG-glycoprotein I anticardiolipin antibody concentration ( $\beta_{2}$-GPIaCL; $55.7 \mathrm{U} / \mathrm{mL}$; normal, $<3.5$ $\mathrm{U} / \mathrm{mL}$ ). An antinuclear factor (ANF) titer was positive at 1:160 with a speckled pattern, and the antisingle-stranded DNA IgG antibody concentration was $100 \mathrm{U} / \mathrm{L}$ (normal, $<10$ ). Serum anti-acetylcholine receptor antibody concentration was $61 \mathrm{nmol} / \mathrm{L}$ (normal, <2). Cerebrospinal fluid (CSF) analysis revealed 3 cells $/ \mathrm{mm}^{3}$; protein; $22 \mathrm{mg} / \mathrm{dL}$; glucose, 56 $\mathrm{mg} / \mathrm{dL} ; \mathrm{C}_{3}, 0.1 \mathrm{mg} / \mathrm{dL} ; \mathrm{C}_{4}, 0.2 \mathrm{mg} / \mathrm{dL} ; \mathrm{IgG}, 1 \mathrm{mg} / \mathrm{dL}$; and $\operatorname{IgM},<1 \mathrm{mg} / \mathrm{dL}$. A two-dimensional echocardiogram showed no evidence of atrial fibrillation, ischemic heart disease, intracardiac thrombi, cardiomyopathy, valvular heart disease, or ventricular septal defect. Repeated electrocardiograms showed regular sinus rhythm.

Four days after stroke onset, thrombolytic therapy (urokinase, 480000 units i.v./day) and anticoagulation (heparin, 10000 units i.v./day) were initiated and continued for 2 weeks, during which hemiparesis improved markedly. Then, in addition to pyridostig- mine bromide, oral prednisolone (30 $\mathrm{mg} /$ day) and oral anticoagulation (potassium warfarin, $1 \mathrm{mg} /$ day) were administered for 18 months and 1 month, respectively. No new stroke or systemic thrombosis occurred. One month after steroid initiation, the serum concentration of $\beta_{2}$-GPIaCL fell to $22.3 \mathrm{U} / \mathrm{mL}$ and that of anti-acetylcholine receptor antibody decreased to $42 \mathrm{nmol} / \mathrm{L}$. The INR was 1.66 , and warfarin was discontinued since bleeding from gastric ulcer occurred. Although the platelet count increased from $5.9 \times 10^{4}$ to $10.8 \times 10^{4} / \mu \mathrm{L}$, aPTT remained prolonged $(53.3 \mathrm{sec})$. After 18 months, serum concentrations of $\beta_{2}$-GPIaCL and anti-acetylcholine receptor antibody were $24.7 \mathrm{U} / \mathrm{mL}$ and $16 \mathrm{nmol} / \mathrm{L}$, respectively. The platelet count was normal $\left(14.5 \times 10^{4} / \mu \mathrm{L}\right)$ and aPTT was no longer prolonged $(41.1 \mathrm{sec})$. INR was 0.98. Attenuation of the right parietal lesion decreased further on $\mathrm{CT}$, and no new lesion was detected by follow-up CT and MRI over 18 months (Figs 2A-D). She had a very slight right hemiparesis mainly in the upper limb, and a slightly nasal voice. Mild weakness in other limbs had disappeared.

\section{DISCUSSION}

An ischemic stroke complicated a long course of generalized MG in the present patient. Serum concentrations of antiphospholipid antibody were elevated; other cerebrovascular risk factors were absent. She had an old lesion in the left frontal lobe and a recent lesion in the right parietal lobe, with intact higher cortical functions. No abnormalities of cerebral arteries were evident on MRA. Multiple small cortical and subcortical lesions were demonstrated in FLAIR images. Over half of patients with APSrelated ischemic stroke reportedly have at least one recurrent ischemic stroke, with $\mathrm{IgG}$ anticardiolipin concentrations over $100 \mathrm{U} / \mathrm{mL}$ associated with the shortest times to a subsequent thrombo-occlusive event [5]. APS has involved atherosclerotic largevessel disease in one-third of cases, small-vessel disease in another third, and cardioembolic disease in one-fifths [6]. Stenosis and occlusion in medium-size arteries have been described angiographically [1], and platelet-fibrin thrombi filling small vessels without signs of vasculitis have been demonstrated histologically in some cases of APS. Multiple subcortical lesions on MRI regarded as infarcts also have been reported in APS [7].

The small, multiple cortical and subcortical infarctions that we demonstrated by FLAIR are consistent with findings in APS [7,8]. Cardioembolic 
thrombi can occur in APS [6,8] without evidence of a cardiac abnormality, as well as atherosclerotic largevessel disease; subsequently recanalized, APS-related thrombi may have resulted in our patient's old frontal and recent parietal infarcts. Infarction with a history of phlebothrombosis, elevated anticardiolipin antibody, and thrombocytopenia fulfilled the diagnostic criteria for APS proposed by Hughes et al. Systemic lupus erythematosus (SLE) can cause occlusion of both large and small cerebral vessels, and often is complicated by APS. As the present case did not fulfill the diagnostic criteria proposed by American Rheumatic Association for SLE despite the positive serum ANF, SLE was excluded as a cause of stroke.

Four reports have assessed on the prevalence of serum IgG antiphospholipid antibodies in $\mathrm{MG}$ patients [1-4]. One study found the antibody to be present at low titer in $40 \%$ of cases (10 of 25 patients; cutoff value, $>2 \mathrm{SD}$ above the control mean) [1], while two other studies found the antibody in 25\% (18 of 71) [4] and 15\% of patients (14 of 94) [2]. In the first two reports [1,4], titers of IgG antiphospholipid antibody were variable, while the third report to no a difference did not specify the titer [2]. In the first report, Colaço et al. [1] considered IgG anti-cardiolipin antibody significant even when titers were very low (below the control mean +2 $\mathrm{SD}$ ); in the second [4], concentrations between $17 \mathrm{U}$ and $90 \mathrm{U} / \mathrm{mL}$. However, Rombos et al. [3] found no significant difference serum IgG antiphospholipid antibody concentrations between MG patients and controls. Even when the incidence of IgG antiphospholipid antibodies was relatively high, the patients did not show clinical manifestations of APS [1-4], possibly because of low titers. The frequency of conventional risk factors for stroke such as hypertension, diabetes mellitus, or atrial fibrillation was lowest in patients whose $\mathrm{IgG}$ anticardiolipin concentrations were very high $\geq 100 \mathrm{U} / \mathrm{mL}$ in a series of consecutive patients with cerebral ischemia found to have antiphospholipid antibodies [5]. In this highly positive group, APS-related abnormalities such as thrombocytopenia and prolonged aPTT were particularly common [5]. Two MG patients with high titers of $\mathrm{IgG}$ anticardiolipin antibodies and clinical manifestations of APS had been reported. A 40-year-old woman with MG for 6 months, with a history of pulmonary embolism and spontaneous abortion, thrombocytopenia, and a $\beta_{2}$-GPIaCL concentration of 125 $\mathrm{U} / \mathrm{mL}$ had small multiple asymptomatic subcortical infarcts on MRI. Prednisolone normalized the platelet count and aPTT [9]. A 32-year-old woman with MG had a history of pulmonary infarction and spontaneous abortion, and developed hemiparesis from MRA- confirmed middle cerebral artery occlusion 12 years after onset of MG. Serum IgG anticardiolipin antibody exceeded $140 \mathrm{U} / \mathrm{mL}$ [10]. No patient including ours fulfilled SLE diagnostic criteria. Like the others, our patient showed a relatively high $\beta_{2}$-GPIaCL concentration $(55.7 \mathrm{U} / \mathrm{mL})$. MG patients, then, may develop APS, with high serum concentrations of $\operatorname{IgG}$ anticardiolipin antibodies being associated with ischemic stroke.

Serum antiphospholipid antibody concentration should be measured if a patient with generalized MG develops venous or arterial thrombosis, spontaneous abortions, or thrombocytopenia. Since our patient was not receiving oral anticoagulation, the INR after 18 months was 0.98. In our patient, as in another [9], prednisolone was useful in decreasing antiphospholipid antibodies, normalizing aPTT and platelet count, and preventing recurrent stroke.

\section{REFERENCES}

1. Colaço CB, Scadding GK, and Lockhart S. Anti-cardiolipin antibodies in neurological disorders; cross-reaction with anti-single stranded DNA activity. Clin Exp Immunol 1987; 68:313-319.

2. Kinoshita I, Motomura M, Nagasato K, Ichinose K, Ohishi $\mathrm{K}$ et al. Antiphospholipid antibodies in patients with myasthenia gravis. Acta Med Nagasaki 1994; 39:41-44.

3. Rombos A, Evangelopoulou-Katsiri E, Leventakou A, Voumvourakis K, Triantafyllou N et al. Serum IgG and IgM anticardiolipin antibodies in neurological diseases. Acta Neurol Scand 1990; 81:243-245.

4. Sanmarco M, and Bernard D. Studies of IgG-class anticardiolipin antibodies in myasthenia gravis. Autoimmunity 1994; 18:57-63.

5. Levine SR, Brey RL, Sawaya KL, Salowich-Palm L, Kokkinos J et al. Recurrent stroke and thrombo-occlusive events in the antiphospholipid syndrome. Ann Neurol 1995; 38:119-124.

6. The Antiphospholipid Antibodies in Stroke Study (APASS) Group. Anticardiolipin antibodies are an independent risk factor for first ischemic stroke. Neurology 1993; 43:2069-2073.

7. Digre KB, Durcan FJ, Branch WD, Jacobson DM, Varner MW et al. Amaurosis fugax associated with antiphospholipid antibodies. Ann Neurol 1989; 25:228232.

8. Fulham MJ, Gatenby P, and Tuck RR. Focal cerebral ischemia and antiphospholipid antibodies: a case for cardiac embolism. Acta Neurol Scand 1994; 90:417-420.

9. Watanabe H, Hakusui S, Yanagi T, Yoshida A, and Yasuda T. A case of antiphospholipid syndrome associated myasthenia gravis. Rinsho Shinkeigaku 1997; 
37:641-644. (in Japanese)

10. Shoenfeld Y, Lorber M, Yucel T, and Yazici H. Primary antiphospholipid syndrome emerging following thymec- tomy for myasthenia gravis: Additional evidence for the kaleidoscope of autoimmunity. Lupus 1997; 6:474-476. 